
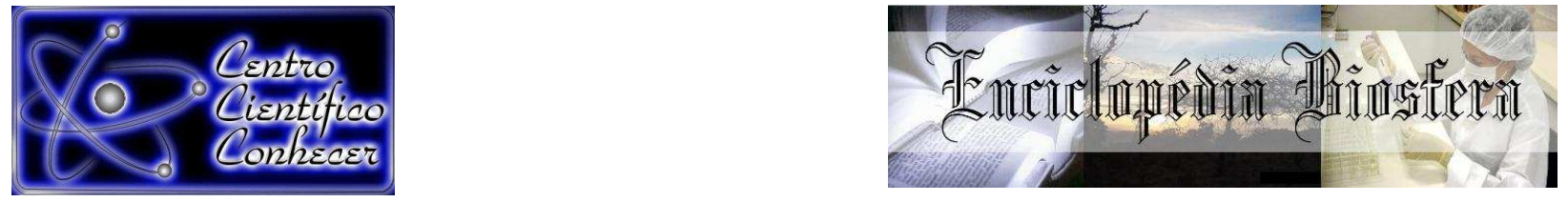

\title{
REPARO DE HÉRNIA INCISIONAL RECIDIVANTE EM UMA GATA COM USO DE TELA DE POLIPROPILENO - RELATO DE CASO
}

Janaína Maria Xavier Corrêa ${ }^{1}$; Luna Oliveira Simões²; Mário Sérgio Lima de Lavor $^{3}$, Elisângela Barboza da Silva ${ }^{4}$

1. Doutoranda em Ciência Animal da Universidade Estadual de Santa Cruz, Ilhéus-Bahia-Brasil - janainamxc@yahoo.com.br

2. Residente em cirurgia de pequenos animais da Universidade Federal da Bahia, Salvador- Bahia-Brasil.

3. Professor Adjunto, Departamento de Ciências Agrárias e Ambientais, Universidade Estadual de Santa Cruz, Ilhéus-Bahia-Brasil.

4. Professora Assistente, Departamento de Ciências Agrárias e Ambientais, Universidade Estadual de Santa Cruz, Ilhéus-Bahia-Brasil.

Recebido em: 08/04/2016 - Aprovado em: 30/05/2016 - Publicado em: 20/06/2016 DOI: 10.18677/Enciclopedia_Biosfera_2016_102

\begin{abstract}
A hérnia incisional é a protrusão de órgãos ou tecidos através de um defeito na cavidade abdominal após procedimento cirúrgico. Pode ocorrer devido a causas iatrogênicas como lambedura no local da incisão, falta de repouso no pós-operatório, não utilização de colar Elizabetano e curativos e consequente infecção ou escolha inadequada da técnica de sutura. O objetivo deste relato de caso foi descrever a correção de hérnia incisional recorrente de um felino utilizando tela de polipropileno. O animal apresentava hérnia incisional recorrente após ovariohisterectomia, sendo esta a segunda herniorrafia para correção do defeito adquirido. Por isso optou-se pela utilização da tela de polipropileno que foi suturada com pontos simples na musculatura. A tutora foi instruída com relação aos cuidados no pós-operatório quanto ao uso de colar Elizabetano, restringir a movimentação, curativos e medicação. Após 10 dias o animal retornou com a ferida cicatrizada e sem aumento de volume no local, os pontos foram retirados. Conclui-se que a utilização da tela de polipropileno foi eficiente no reparo de hérnia incisional recidivante em felino por ocluir o defeito na musculatura e diminuir a tensão na sutura associado aos cuidados pós-operatório recomendados.
\end{abstract}

PALAVRAS-CHAVE: Cirurgia Veterinária, Cirurgia Reparadora, Herniorrafia, Implante de tela cirúrgica

\section{POLYPROPYLENE MESH IMPLANT TO REPAIR A RECURRENT INCISIONAL HERNIA IN A FEMALE CAT - CASE REPORT}

\begin{abstract}
Incisional hernia is a protrusion of an organ or tissue through a defect in abdominal wall after a surgical procedure. The possible causes are iatrogenic, such as licking the wound, lack of rest in postoperative period, not use Elizabethan collar, infections, or wrong choice of suture techniques. The objective of this case report is describes the technique to deal a recurrent incisional hernia in a female cat after an
\end{abstract}


ovariohysterectomy surgery, using a polypropylene mesh implant. After surgery, the animal develops an incisional hernia, and was subject a new procedure to hernia repair. Then, the animal has developed incisional hernia the second time, and for that reason it was used polypropylene mesh to close the hernia ring. In the Abdominal muscle defect, the mesh implant was sutured in a simple interrupted pattern with nylon. The cat owner was oriented about post surgical rest and care. The animal returned ten days after the hernia surgery with wound healed and without recurrence. Therefore, it can be concluded that the use of polypropylene mesh was effective in relapsing incisional hernia repair in feline to occlude the defect in the muscles and decrease the tension on the suture associated with the recommended post-operative care.

KEYWORDS: Herniorrhaphy, Mesh surgical implants, Reconstructive surgery, Veterinary surgery

\section{INTRODUÇÃO}

As hérnias incisionais são adquiridas e formadas quando há ruptura de uma cavidade fechada após um procedimento cirúrgico. Podem desenvolver-se após laparotomia, principalmente na linha média ventral, a qual apresenta maior possibilidade de completa deiscência e evisceração. Sua prevalência é de $6,5 \% \mathrm{em}$ cães e gatos (SMEAK, 2002).

Os fatores de risco para a hérnia incisional aguda são: pressão intraabdominal causada pela dor, tecido adiposo retido entre as bordas da sutura, material de sutura inadequado, infecção, tratamento crônico por esteróides e cuidados pós-operatórios insuficientes (SMEAK, 2002). Aumentam o risco: atividade excessiva do animal, episódios violentos de tosse ou esforço de defecação no período pós-operatório, obesidade, gestação ou distenção de órgãos em decorrência de obstrução (READ \& BELLENGER, 2002; SMEAK, 2002).

As principais causas de hérnia incisional são erro na técnica, infecção, ruptura da sutura, deslizamento ou afrouxamento dos nós e o corte do tecido pelo fio da sutura (READ \& BELLENGER, 2002; FOSSUM, 2005).

As hérnias incisionais podem ser agudas, até os sete dias de pós-operatório, ou crônicas, notadas semanas ou anos mais tarde (SMEAK, 2002).

O reparo de hérnias abdominais ocupa lugar importante na rotina cirúrgica, tanto veterinária, quanto humana. Seu propósito é retornar o conteúdo viável para sua cavidade e ocluir as bordas musculares com segurança (READ \& BELLENGER, 2002). Em pacientes com reparo de hérnias, o exercício deve ser restrito no mínimo durante duas semanas e a ferida cirúrgica deve ser tratada adequadamente para evitar que ocorra infecção (FOSSUM, 2005).

A melhor abordagem é a incisão sobre o aumento de volume, com atenção a uma exposição cirúrgica e acesso adequados, pois os tecidos podem estar friáveis. Pode ser necessário ainda o alargamento do anel herniário para um acesso razoável. Os tecidos desvitalizados devem ser excisados e as aderências devem ser desfeitas por divulsão ou dissecção (READ \& BELLENGER, 2002).

A oclusão do anel pode ser realizada pela aproximação direta dos tecidos locais com sutura em estruturas com força de retenção suficiente para resistir à ruptura por meio de acesso cirúrgico direto ou por laparoscopia. Esta segunda técnica possui menor morbidade e menor tempo de recuperação (CLAUS et al., 2011; MOTTIN et al., 2011; LOBATO et al., 2014; PERES et al., 2014), mas para isto se faz necessário o equipamento específico. Sendo assim rotineiramente na 
medicina veterinária se utiliza a técnica cirúrgica tradicional. Também podem ser utilizados retalhos de tecido autógeno, como a fáscia lata ou a pele ou ainda, exógenos sintéticos como telas. O fio de sutura deve suportar as pressões intraabdominais até que a cicatriz adquira resistência suficiente (GIANLUPI \& TRINDADE, 2004).

As telas ou malhas podem ser utilizadas de duas maneiras no reparo das hérnias incisionais. A primeira ocorre durante o reparo primário, a fim de reforçá-lo. Após o fechamento fascial, a tela é suturada sobre o músculo. A segunda forma, na impossibilidade de aproximação das bordas musculares e/ou grande perda tecidual, é a utilização da tela como um substituto, inserindo-a diretamente no defeito. Essa técnica permite a diminuição da tensão sobre o reparo, porém haverá a possibilidade de deiscência das suturas de fixação da tela pela pressão fisiológica exercida sobre a mesma (MILLIKAN, 2003).

Existem mais de 80 tipos de telas para o reparo das hérnias abdominais. Podem ser de materiais sintéticos inabsorvíveis, como os derivados do polipropileno e do poliéster. As telas de polipropileno podem ser monofilamentares, bifilamentares ou multifilamentares. A tela monofilamentar foi a primeira e continua sendo a tela mais utilizada (FOSSUM, 2002). Alguns autores citam as telas de polipropileno envolta por tecido fibroso, que diminuem as aderências que podem ocorrer na tela comum (RICCIARDI et al., 2012) Os materiais sintéticos absorvíveis, como os derivados de ácido glicólico e da poliglactina (FOSSUM, 2002). E também membranas biológicas como pericárdio bovino (VIDOR et al., 2013).

Cirurgiões devem evitar a utilização de telas não absorvíveis em hérnias infectadas ou com alto risco de infecção (ALDER et al., 2006). A suscetibilidade dessas telas para colonização bacteriana e infecção crônica ocorre porque as bactérias aderem aos polímeros da tela e geram um biofilme que as protege das defesas imunológicas do hospedeiro a da ação dos antibióticos (ALDER et al., 2006).

Em modelo experimental de indução de hérnia incisional em ratos observouse que a utilização da tela de polipropileno e de fio absorvível sintético são eficazes para o fechamento das hérnias com maior resistência tênsil que o grupo controle (MAZZINI \& MANTOVANI, 1999). Em animais de grande porte, as telas de polipropileno também são utilizadas em casos de hérnias abdominais com êxito e boa recuperação do animal (FERREIRA et al., 2014).

Em caso de hérnias recidivantes e crônicas, há um agravante em relação à resistência e contração da musculatura do anel herniário, assim como em casos de hérnias perineais há a fragilidade da musculatura afetada. Nesses dois casos indicase o uso da tela que auxilia no fechamento do anel mesmo tendo as musculatura comprometida por idade do paciente ou pelo tempo de existência da hérina (LEAL et al., 2012)

As taxas de recidiva de hérnias incisionais variam de $10 \%$ a $50 \%$ após o reparo primário e de $3 \%$ a $17 \%$ quando há utilização de telas ou membranas biológicas (MILLIKAN, 2003; GIANLUPI \& TRINDADE, 2004). O objetivo deste trabalho foi descrever o uso da tela de polipropileno para fechamento de uma hérnia incisional recidivante em felino.

\section{RELATO DE CASO}

Foi atendida no Hospital veterinário da Universidade Estadual de Santa Cruz, uma fêmea felina, com um ano e oito meses de idade, castrada. A proprietária relatou que surgiu um aumento de volume com consistência flutuante, na região 
abdominal há seis meses e o animal apresenta dificuldade para defecar. Isso aconteceu 15 dias após a ovariohisterectomia. Em uma clínica particular foi diagnosticada hérnia incisional e foi realizada a cirurgia para correção, porém após 15 dias a hérnia reapareceu.

Foi coletado sangue para realizar o hemograma e análise bioquímica para uréia, creatinina, ALT e AST, cujos valores estavam dentro da normalidade. Também foi realizada ultrassonografia que confirmou a presença de hérnia ventral incisional com presença de segmentos intestinais no conteúdo. O animal foi encaminhado para procedimento de herniorrafia.

Para o procedimento cirúrgico, o animal foi pré medicado com associação de morfina $(0,3 \mathrm{mg} / \mathrm{kg})$, midazolam $(0,2 \mathrm{mg} / \mathrm{Kg})$ e cetamina $(5 \mathrm{mg} / \mathrm{kg})$, via intramuscular, feita a tricotomia da região abdominal. E após 20 minutos foi induzido com $3 \mathrm{mg} / \mathrm{kg}$ de propofol intravenoso e mantido sob anestesia geral inalatória $2 \mathrm{~V} \% \mathrm{com}$ isoflurano em $100 \%$ de oxigênio (200 $\mathrm{ml} / \mathrm{kg} / \mathrm{min}$ ) por meio de um sistema sem reinalação (Baraka).

Após a estabilização anestésica, o animal foi posicionado em decúbito dorsal, realizada a anti-sepsia (Figura $1 \mathrm{~A}$ ) e fixados os panos de campo estéreis. Foi feita uma incisão elíptica, sobre a hérnia e retirado o excesso de pele. Ao avaliar a herniação observou-se que em seu conteúdo havia segmentos intestinais viáveis e omento (Figura 1B) e aderências que foram desfeitas por meio de divulsão, ao reduzir o conteúdo herniário notou-se que haviam dois anéis herniários na parede externa do abdome (Figura 1C). Assim foi feita uma incisão e os dois pontos herniados foram convertidos em um (Figura 2A). Como se tratava de uma área extensa para ser suturada e, devido a recorrência da hérnia, foi fixada uma tela sintética de polipropileno monofilamentar nas paredes do defeito por meio de sutura interrompida simples e fio de náilon 2-0 (Figura 2B e C). Fez-se a redução do subcutâneo com fio poliglactina 910 3-0 padrão intradérmico e a síntese da pele foi feita com sutura Wolf e fio náilon 0 (Figura 2D). Foi colocado um curativo com gaze e atadura com compressão moderada no local.

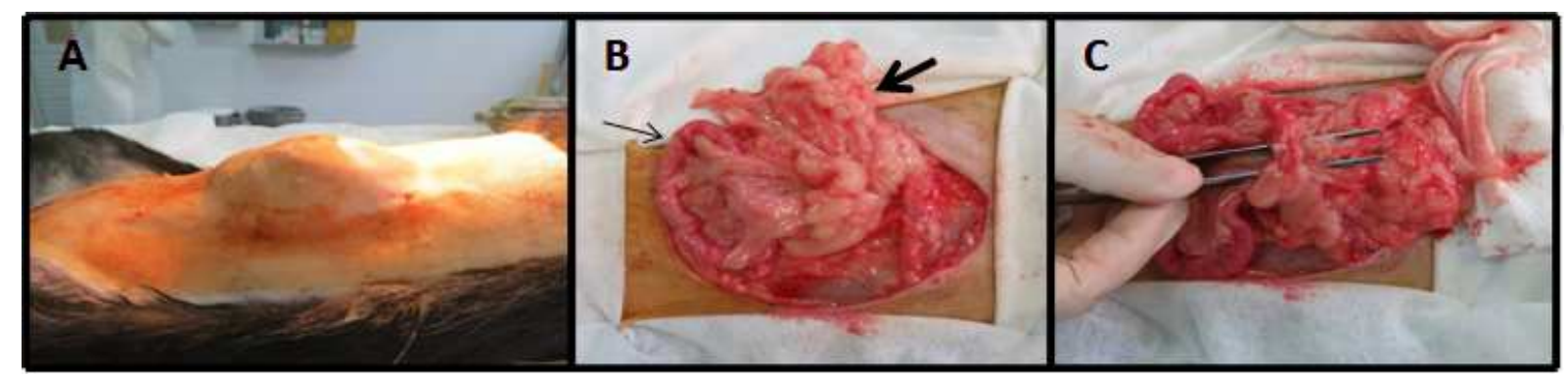

FIGURA 1: Imagens fotográficas do trans-operatório da herniorrafia de uma gata. A: Hérnia incisional abdominal ventral após tricotomia e antissepsia préoperatória. B Conteúdo herniário, alça intestinal (seta fina) e omento (seta larga). C: Pinça atravessando os dois anéis herniários. Fonte: SILVA, E.B. 


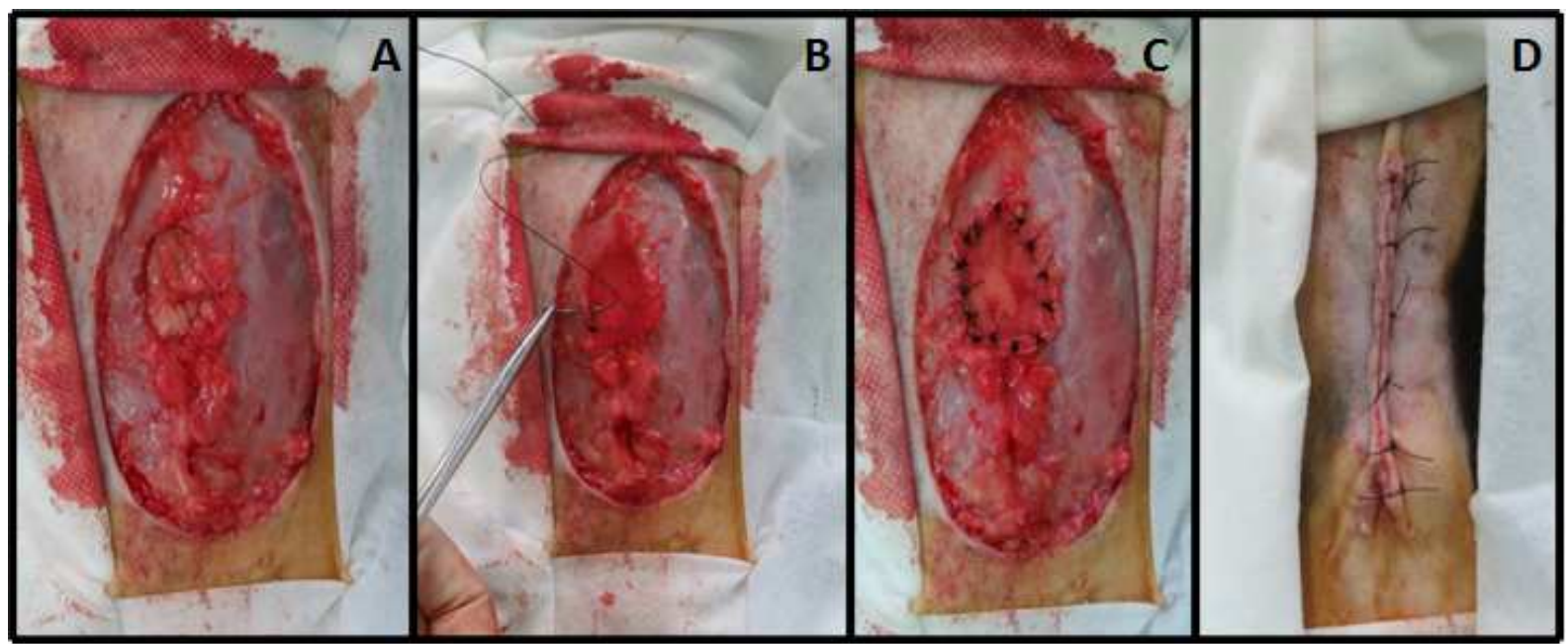

FIGURA 2: Imagens fotográficas do trans-operatório de herniorrafia em gata. A: Anel herniário pronto para receber o reparo com a tela de polipropileno. B: início da aplicação da tela com fio de náilon 2-0 e ponto simples separado. C: Anel herniário reparado com a tela. D: Ferida cirúrgica do pós-operatório imediato. Fonte: SILVA, E.B.

No pós-operatório o animal foi medicado com enrofloxacina $(5 \mathrm{mg} / \mathrm{kg})$ uma vez ao dia durante 10 dias, meloxicam $(0,1 \mathrm{mg} / \mathrm{kg})$ uma vez ao dia durante três dias ambos por via oral e uso tópico de digluconato de clorexidine $10 \%$ uma vez ao dia durante 10 dias sobre a ferida, e recomendado repouso e utilização do colar Elizabetano.

O animal retornou ao hospital veterinário 10 dias após a herniorrafia, a ferida cirúrgica estava completamente cicatrizada e pontos foram retirados (Figuras $3 \mathrm{~A}$ e B).

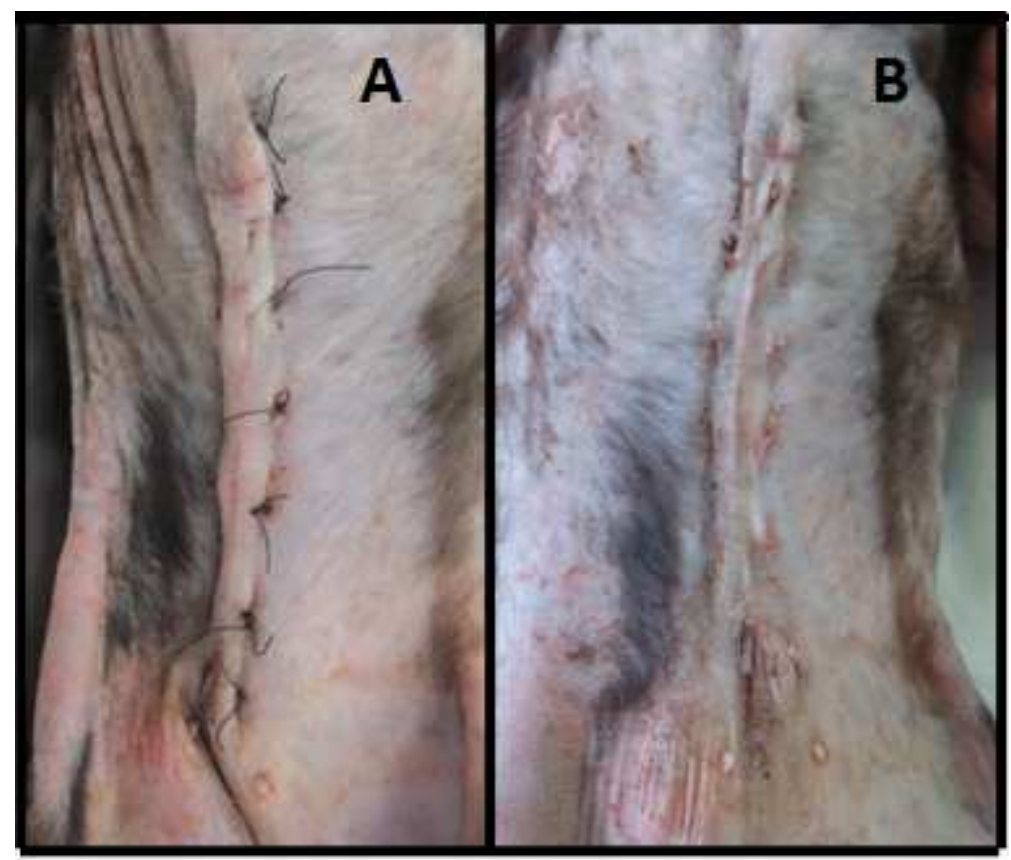

FIGURA 3: Imagem fotográfica da ferida cirúrgica após a herniorrafia com tela de polipropileno 13 dias depois do procedimento. A: Ferida com pontos padrão Wolf fio de náilon 0 . B: Ferida após retirada dos pontos. Fonte: SILVA, E.B. 


\section{DISCUSSÃO}

Como relatado por READ \& BELLENGER (2002), SMEAK (2002), atividade excessiva do animal pode levar a uma hérnia incisional o que provavelmente foi responsável pela aparição inicial da hérnia e a sua recidiva após a ovariohisterectomia, já que a tutora relatou que não conseguiu manter o animal em repouso.

$\mathrm{Na}$ medicina humana muitos pacientes submetidos a cirurgia abdominal desenvolvem hérnia incisional e ainda quando a laparotomia é realizada como uma reoperação, a taxa de hérnia incisional também é elevada (ARGUDO et al., 2014). Um estudo feito por PEREIRA et al., (2013) mostra que 54\% dos médicos acreditam que o fator de risco mais importante é a técnica empregada para o fechamento de laparotomias. Esse também é um aspecto importante na medicina veterinária, porque os pacientes veterinários não permanecem em repouso após a cirurgia, assim a utilização de um fio que é absorvido mais rápido ou a utilização de suturas em padrão contínuo na linha média podem ser responsáveis pela herniação.

A tutora foi orientada a manter o animal em um local com movimentação restrita e uso de colar Elizabetano, somada a utilização da tela de polipropileno diminui a probabilidade de recidiva (MILLIKAN, 2003; GIANLUPI \& TRINDADE, 2004; ALDER at al., 2006).

O uso do colar Elizabetano e proteção da ferida com bandagem ou roupas cirúrgicas são muito importantes, principalmente em felinos, porque estes possuem a língua áspera e tem o hábito de se lamber o que é agravado com o prurido e seroma da ferida cirúrgica (SMEAK, 2002).

A vantagem do uso de telas no reparo de hérnias recidivantes é que ela diminui a tensão no local da sutura, diminuindo a chance de uma nova ocorrência (MILLIKAN, 2003; GIANLUPI \& TRINDADE, 2004). Sendo que a técnica utilizando a tela de polipropileno é considerada padrão ouro para correção de hérnia primária e hérnia incisional (ARMELINO et al., 2006). Essas características justificam o sucesso do procedimento relatado neste trabalho.

ARGUDO et al., (2014) descrevem que o uso profilático de telas sintéticas para prevenir a hérnia incisional em pacientes submetidos a laparotomia é seguro e eficaz. Eles observaram redução da incidência de hérnia incisional em pacientes submetidos a laparotomia contaminada em cirurgia de emergência em que utilizou a tela sintética preventiva.

Muitas vezes os implantes de telas para herniorrafia geram complicações como reação inflamatória intensa, aderências (QUITZAN et al., 2003; RICCIARDI et al., 2012) e infecção em torno de $12,5 \%$ dos casos (PERES et al., 2014). Essas ocorrências não foram observadas no pós-operatório deste animal.

Outra complicação como hematoma decorrente da dissecção dos tecidos para implantar a prótese por meio da técnica aberta pode ocorrer (CLAUS et al., 2011). Como descrito neste caso, embora a hérnia apresentasse aderências e um conteúdo volumoso, não foi observado hematoma.

O uso da tela proporcionou um procedimento seguro e eficaz (MOTTIN et al., 2011), solucionando o problema crônico, pois já haviam sido realizados dois procedimentos na tentativa de redução da hérnia, visto que a tensão do local não permitia a herniorrafia tradicional.

\section{CONCLUSÃO}

A tela de polipropileno é uma boa opção para a correção de hérnia incisional recidivante, pois diminui a tensão da linha de sutura evitando uma nova ocorrência. 
A orientação do proprietário quanto aos cuidados pós-operatórios é importante para a recuperação do paciente e o sucesso do procedimento cirúrgico livre de complicações.

\section{REFERÊNCIAS}

AEMELLINO, M.F.; DE STEFANO, G.; SCARDI, F.; FORNER, A.L.; AMBROSINO, F.; BELLOTTI, R.; ROBUSTELLI, U. Use of permacol in complicated incisional hérnia. Chirurgia Italiana, v. 58, n.8, p. 627-630, 2006. Disponível em: < http://www.ncbi.nlm.nih.gov/pubmed/17069192>.

ALDER, A.; BELLOWS, C. F.; HELTON, W. S. Abdominal wall reconstruction using biological grafts: present status and future opportunities. Expert Review of Medical Devices, $\quad$ v. $3, \quad 2006 . \quad$ Disponível em: <http://www.ncbi.nlm.nih.gov/pubmed/17064250>. doi: 10.1586/17434440.3.5.657

ARGUDO, N.; PEREIRA,J.A.; SANCHO,J.J.; MEMBRILHA, E.; PONS, M.J.; GRNADE, L. Prophylactic synthetic mesh can be safely used to close emergency laparotomies, even in peritonitis. Surgery, v. 156, n.5, p.1238-12-44, 2014. Disponível em: http://dx.doi.org/10.1016/j.surg.2014.04.035

CLAUS, C.M.P.; LOUREIRO, M.P.; DIMBARRE, D.; CURY, A. M.; CAMPOS, A. C. L.; COELHO, J.C.U. Hernioplastia incisional laparoscópica. Experiência de 45 casos. Arquivos Brasileiros de Cirurgia Digestiva, v.1, n.24, p. 121-125, 2011.

FERREIRA, A.G.G.; CATUSSI, A. D.; BORTOLATO, B.L.C.;MEIRA, J.S.D.; GADDINI, I.R.; ROSADO, L.V.; BORNIOTTI, D.F.; TOMIO, T.E.; ZAVILENSKI, R. B.; TRAMONTIN, R. S.; RIBEIRO, M.G. Correção de hérnia abdominal traumática, com uso de tela de polipropileno em égua. Revista Ciência Veterinária e Saúde Pública, v.1, supl.1, p.84, 2014.

FOSSUM, T. W. Cirurgia da cavidade abdominal - Hérnias umbilicais e abdominais. In: Fossum, T.W. Cirurgia de Pequenos Animais. São Paulo: Roca, 2005, p. 205208.

GIANLUPI, A., TRINDADE, M. R. M. Comparação entre o uso do fio inabsorvível (polipropileno) e fio absorvível (poliglactina 910) na fixação de prótese de polipropileno em correção de defeitos músculo-aponeurótico da parede abdominal. Estudo experimental em ratos. Acta Cirúrgica Brasileira. São Paulo, v. 19, 2004. Disponível em: <http://dx.doi.org/10.1590/S0102-86502004000200003>. doi: $10.1590 /$ S0102-86502004000200003

LEAL, L.M.; MORAES, P.C.;SOUZA, B.; MACHADO, M.R.F. Herniorrafia perineal com tela de polipropileno em cão - relato de caso. Revista Científica Eletrônica de Medicina Veterinária, n.18, 2012. Disponível em: < http://faef.revista.inf.br/>.

LOBATO, R.S.; BELBEL,J.C.R.A.; MORALES, F.A.; SEPTIEM, G.; LUCAS, F.J.M.; ESTEBAN, M.L. Estudio de coste-beneficio comparando la reparacion de la hérnia ventral abierta y laparoscópica. Cirugia Espanhola, n.92, v.8, p.553-560, 2014. 
MAZZINI, D.L.; MANTOVANI, M. Fechamento da parede abdominal com afastamento parcial das bordas da aponeurose utilizando sobreposição com telas de vicry ou marlex em ratos. Acta Cirúrgica Brasileira, v.14, 1999. Disponível em: <http://dx.doi.org/10.1590/S0102-86501999000100006>. doi: 10.1590/S010286501999000100006

MILLIKAN,K. M. Incisional hernia repair. Surgical Clinics of North America, v.83, 2003.

MOTTIN,C.C., RAMOS, R.J., RAMOS, M.J. Utilização do sistema prolene de hérnia (PHS) para o reparo de hérnias inguinais. Revista do Colégio Brasileiro de Cirurgiões, v.1, n.38, 2011. Disponível em: <http://www.scielo.br/rcbc>.

PEREIRA, J.A.; LÓPEZ-CANO, M.; MARSAL, F.; FELIU, X. Results of a national survey on abdominal wall closure. Cirugía Española, v. 10, n.91, p. 645-650, 2013. Disponível em: < http://www.ncbi.nlm .nih.gov/pubmed/23764518> doi: 101016

PERES, M.A.O., AGUIAR, H.R., ANDREOLLO, N.A. Tratamento cirúrgico da hérnia incisional subcostal com tela de polipropileno - análise de resultados tardios. Revista do Colégio Brasileiro de Cirurgiões, v.2, n.41, 2014.

QUITZAN, J.G.; RAHAL, S.C.; ROCHA, N.S.; CROCCI, A.J. Comparação entre pericárdio bovino preservado em glicina e malha de poliéster no reparo de falhas da parede abdominal em ratos. Acta Cirúrgica Brasileira, v. 18, n.4, p. 297-301, 2003. Disponível em: <http://dx.doi.org/10.1590/S0102-86502003000400007>

READ, R. A.; BELLENGER, C. R. Hérnias. In: Slatter, D. Text book of small animal surgery. Philadelphia: Saunders, 2002, p. 529-533.

RICCIARDI, B.F., CHEQUIM, L.H., GAMA, R.R., HASSEGAWA, L. Correção de hérnia abdominal com tela envolta por tecido fibroso - estudo em ratos Wistar. Revista do Colégio Brasileiro de Cirurgiões, v.39, n.3, p.195-200, 2012.

SMEAK, D.D. Management and prevention of surgical complications associated with small animal abdominal herniorraphy. Problems in Veterinary Medicine, v. 1, 2002.

VIDOR, S.B.; MARQUES, J.M.V.; MOURA, L.F.L.; GOMES, C.; PAZ, A.H.; GOMES, H.M.; MEURER, L.; BARROS, R.R.; GUIMARÃES, K.M.; CIME-LIMA, E.O.; CONTESINI, E.A. Reparo de hérnia abdominal com pericárdio bovino associado a células-tronco mesenquimais em ratos Wistar. Acta Scientiae Veterinariae, v.41, 2013. Disponível em: < http://www.ufrgs.br/actavet/41/PUB\%201102.pdf>. 